\title{
Effectiveness of Low-Level Laser Irradiation in Reducing Pain and Accelerating Socket Healing After Undisturbed Tooth Extraction
}

\author{
Farzaneh Ahrari ${ }^{*}{ }^{*}$, Majid Eshghpour ${ }^{1}$, Reza Zare ${ }^{2}$, Samaneh Ebrahimi ${ }^{3}$, Amir Fallahrastegar ${ }^{1}$, Hossein Khaki ${ }^{4}$ \\ ${ }^{1}$ Dental Research Center, School of Dentistry, Mashhad University of Medical Sciences, Mashhad, Iran \\ ${ }^{2}$ Oral \& Maxillofacial Diseases Research Center, School of Dentistry, Mashhad University of Medical Sciences, Mashhad, Iran \\ ${ }^{3}$ Department of Operative Dentistry, School of Dentistry, Islamic Azad University, Isfahan (Khorasgan/Branch), Isfahan, Iran \\ ${ }^{4}$ Private Practice, Mashhad, Iran
}

\author{
*Correspondence to \\ Farzaneh Ahrari, \\ Dental Research Center, School of \\ Dentistry, Mashhad University of \\ Medical Sciences, Vakilabad Blvd, \\ Mashhad, Iran. \\ Fax: +98 5118829500 \\ Tel: +98513 8829504 \\ Email: Farzaneh.Ahrari@gmail.com \\ Published online June 21, 2020
}

\begin{abstract}
Introduction: This study aimed to determine the effect of low-level laser therapy (LLLT) on reducing complications following tooth extraction.

Methods: This randomized clinical trial consisted of 40 subjects who underwent lower molar extraction. The patients were randomly assigned to 4 groups. Group 1 was irradiated with a 660 $\mathrm{nm}$ laser $(200 \mathrm{~mW}, 30$ seconds radiation to lingual, buccal and occlusal surfaces of the socket, $6 \mathrm{~J} /$ area). In group 2, an $810 \mathrm{~nm}$ laser was applied similar to group 1. In group 3, a combination of 660 and $810 \mathrm{~nm}$ lasers was used. The patients in group 4 served as a placebo group. LLLT was performed after 0.5-1 hour of extraction and 2 days later. The participants were asked to record pain degree using a visual analogue scale (VAS) over 7 days. The amount of wound healing was evaluated on the third and seventh days.

Results: There was no significant difference in pain scores among the groups at any of the assessment intervals $(P>0.05)$. The between-group differences in wound healing scores were small and insignificant $(P>0.05)$.

Conclusion: LLLT with $660 \mathrm{~nm}$ or $810 \mathrm{~nm}$ lasers or their combination had no greater effect than the placebo laser for reducing the complications of tooth extraction.

Keywords: Laser therapy; Low-level light therapy; Pain; Tooth extraction; Wound healing.
\end{abstract}

\section{Introduction}

Tooth extraction is the final stage of severe oral diseases. Although there are several reasons for extracting the teeth, but dental caries and periodontal problems are considered as the most prominent reasons throughout the world. ${ }^{1}$ After tooth extraction, several histological and histochemical responses occur to heal the extraction site. The hemorrhage in the alveolar socket is followed by the formation of a blood clot, the organization of a fibrin clot, the migration of the epithelial layer over the wound surface, the resorption of damaged tissues, and finally the new bone formation. ${ }^{2}$

Complications following tooth extraction are rare and mostly minor. Some patients experience mild to moderate pain following tooth extraction. The presence of an empty socket is annoying for most patients as it may be surrounded by sharp bony edges and filled with food debris after eating. This problem is generally solved within a few weeks after extraction. Due to the great number of patients who undergo tooth extraction worldwide, the prevention or treatment of likely complications becomes important. $^{3}$

Low-level laser therapy (LLLT) is a novel branch of medicine that employs low-power lasers to living tissues in order to stimulate and enhance cell function or relieve pain. The effectiveness of LLLT in reducing pain and swelling, stimulating nerve function, enhancing revascularization and improving the wound healing process has been confirmed in several studies. ${ }^{4-9}$

There are few and controversial reports regarding the effect of laser therapy on attenuating possible complications after tooth extraction. Some studies demonstrated the beneficial effects of laser therapy on reducing pain, swelling and trismus after the surgical removal of impacted lower third molars. ${ }^{10-18}$ Others revealed that the application of LLLT enhanced bone healing and mineralization in the sockets of rats exposed to diode laser radiation. ${ }^{19-23}$ However, some studies

Please cite this article as follows: Ahrari F, Eshghpour M, Zare R, Ebrahimi S, Fallahrastegar A, Khaki H. Effectiveness of low-level laser irradiation in reducing pain and accelerating socket healing after undisturbed tooth extraction. J Lasers Med Sci. 2020;11(3):274-279. doi:10.34172/jlms.2020.46. 
found no additional benefits of using low-level lasers over the placebo in several conditions such as releasing pain after the extraction of primary ${ }^{24}$ and permanent ${ }^{25}$ teeth, reducing pain and swelling following third molar surgery, ${ }^{26-28}$ improving pulp tissue healing after direct pulp capping in dogs, ${ }^{29}$ and attenuating chronic orofacial pain in patients with temporomandibular dysfunction (TMD).$^{30}$

This randomized, double-blind controlled trial was conducted to investigate the efficacy of LLLT in relieving pain and accelerating the healing of the tooth socket after the extraction of lower molar teeth.

\section{Patients and Methods}

Patient Selection and Assignment

This randomized clinical trial included 40 patients who referred to the Department of Oral and Maxillofacial Surgery, School of Dentistry, Mashhad University of Medical Sciences, Mashhad, Iran and underwent molar extraction in the lower arch. The subjects were recruited if they had the following inclusion criteria: 1) the age range between 18 and 50 years; 2) no history of underlying systemic disorders; 3 ) no active treatment with antibiotics, steroidal and non-steroidal anti-inflammatory drugs within the past month; and 4) no sign of periodontal problems in the target teeth. The exclusion criteria were as follows: 1) the occurrence of a dry socket (alveolar osteitis) at follow-up appointments; 2) the occurrence of trauma during the extraction process e.g. root fracture, bone removal or soft tissue damage; 3 ) the presence of smoking habit, pregnancy or breastfeeding in females; and 4) patients who had more than one tooth extraction at the same time.

\section{Operation Protocol}

Baseline clinical examinations were performed for each patient and after that, the patients underwent local anesthesia by $2 \%$ lidocaine with 1:100000 epinephrine (4\% prilocaine for patients with controlled hypertension). Two oral and maxillofacial surgeons extracted the teeth atraumatically and placed a sterile gauze on the sockets. The patients received usual recommendations following tooth extraction and were then referred to the Laser Department of Mashhad Dental School for laser therapy.

\section{Patient Assignment and Blinding}

The participants were randomly assigned to 4 groups using a table of random numbers. The details of the allocated groups were recorded on cards contained in sequentially numbered, sealed, and opaque envelopes. These cards were prepared by an independent person who was not involved in the study protocol. Once the patient underwent tooth extraction and agreed to participate in the trial, the allocation assignment was revealed by opening the envelope by this independent person.

Laser therapy was contemplated by an experienced operator. To provide the double-blind design of the study, neither the participant nor the subject who assessed the outcomes was aware of the group assignment.

\section{Laser Treatment Protocol}

Following random assignment, the patients in group 1 (low-level red laser) received irradiation from an indiumgallium-aluminum-phosphide (InGaAlP) low-level laser (Thor DD2 Control Unit, Thor, London, UK). The laser emitted a wavelength of $660 \mathrm{~nm}$ and operated at the output power of $200 \mathrm{~mW}$ at an approximately $10 \mathrm{~mm}$ distance to the target area. The target areas were the lingual, buccal and occlusal surfaces of the extraction socket. The irradiation was performed for 30 seconds to each target area, delivering $6 \mathrm{~J}$ of energy with energy density of 4.21 $\mathrm{J} / \mathrm{cm}^{2}$ per area. Laser exposure was performed after 30 to 60 minutes of extraction (day 1) and 2 days later (day 3 ).

The subjects in group 2 (low-level infrared laser) were irradiated with a gallium-aluminum-arsenide (GaAlAs) low-power laser (Thor DD2 Control Unit). This laser emitted a wavelength of $810 \mathrm{~nm}$ at the power of $200 \mathrm{~mW}$. The target areas and the duration of irradiation were similar to that described in group 1, but the surface area of the probe was different. Therefore, $6 \mathrm{~J}$ of energy was delivered to each surface with energy density of $21.4 \mathrm{~J} /$ $\mathrm{cm}^{2}$, considering the surface area of $0.28 \mathrm{~cm}^{2}$ for the probe.

In group 3 (combination laser therapy), a combination of InGaAlP and GaAlAs diode lasers was used with an exposure time of 15 seconds each. The energy delivered to the target area by the red or infrared lasers was $3 \mathrm{~J}$ with energy density of $2.1 \mathrm{~J} / \mathrm{cm}^{2}$ for the red wavelength and $10.7 \mathrm{~J} / \mathrm{cm}^{2}$ for the infrared wavelength.

The patients in group 4 (placebo) were considered as the control in which the treatment was the same as that in group 1 but with no laser radiation.

\section{Post-operative Evaluation}

A visual analogue scale (VAS) was used to assess the degree of pain perceived by the patients. This scale ranged from 0 to 10 with 0 (the left side) representing no pain and 10 (the right side) indicating the most terrible pain. The patients were asked to mark the degree of pain perceived on the VAS at bedtime for 7 days following tooth extraction. The patients were recommended to take ibuprofen $400 \mathrm{mg}$ in painful conditions and record the number of consumption.

Post-operative photographs were taken from the extraction sockets on days 3 and 7 after tooth extraction using Nikon digital camera equipped with a macro lens (Nikon Inc, Tokyo, Japan). The photographs were scored by an oral and maxillofacial surgeon who was blinded to the group assignment. The rater was asked to score the degree of healing on a $10-\mathrm{cm}$ scale, where 0 (the left side) indicated no healing and 10 (the right side) indicated complete healing of the extraction socket. Scoring was based on the following 2 criteria: the degree 
of edge approximation and the presence or absence of inflammation. ${ }^{31}$ The examiner repeated the scoring of 40 images 1 week later to determine the systematic error of the measurements.

\section{Statistical Analysis}

The Shapiro-Wilk test was run to determine the normality of the data. The intraexaminer reliability in scoring the photographs was assessed by the paired-samples $t$ test. The differences in the distribution of sex and age among the groups were assessed by the Fisher exact test and the Kruskal-Wallis test, respectively. The Kruskal-Wallis test was also applied to indicate any significant differences in VAS scores between the study groups. The Friedman test was employed to determine the differences in pain severity in each group over seven days, followed by the Wilcoxon signed rank test for pairwise comparisons. One-way analysis of variance (ANOVA) was run to assess any significant difference in wound healing scores among the groups. Statistical analysis was performed by SPSS (version 11.5, SPSS Inc, Chicago, IL), and $P$ values less than 0.05 were considered to be statistically significant.

\section{Results}

The sample consisted of 22 males and 18 females, ranging in age from 18 to 65 years (mean age 38.5 years). The paired-samples $t$ test revealed no significant difference in wound healing scores between the repeated measurements $(P>0.05)$.

Table 1 demonstrates the demographic data including the participants' sex and age. The groups were well matched in the demographic data according to the statistical analysis $(P>0.05$; Table 1$)$.

Table 2 presents the descriptive statistics regarding pain values over seven days in the study groups. The
Kruskal-Wallis test indicated that there was no significant difference in pain scores among the groups at any of the assessment intervals $(P>0.05$; Table 2$)$. The results of the Friedman test indicated a significant difference in VAS scores over the period of the experiment in all groups $(P<0.05$; Table 2$)$. Further analysis revealed that in all groups, pain degree was significantly lower on days 6 and 7 , as compared to the first day $(P<0.05)$.

Table 3 indicates the descriptive data regarding wound healing scores in the study groups throughout the experiment. On days 3 and 7 after extraction, the greatest wound healing scores were observed in group 1 (low-level red laser). However, the difference between the groups was small and the results of ANOVA revealed no significant difference in the degree of wound healing among the groups at any of the assessment intervals $(P>0.05$; Table 3$)$.

\section{Discussion}

This randomized controlled trial evaluated the effects of LLLT on attenuating pain and improving the healing of extraction wounds. The outcomes of this study indicated that LLLT had no additional benefit over the placebo for reducing pain and enhancing the healing rate following the extraction of lower molar teeth. The present study benefitted from a $660 \mathrm{~nm}$ (red) and an $810 \mathrm{~nm}$ (infrared) low-power lasers. The red laser has a low penetration depth (less than $10 \mathrm{~mm}$ ) and is suitable for the treatment of superficial wounds, whereas the penetration depth of the infrared laser reaches about $2-3 \mathrm{~cm} .{ }^{30}$ The red and infrared wavelengths were irradiated together in the third group of this study because it is assumed that the mixed application of these lasers might have a synergistic effect on biostimulation. ${ }^{32}$ The laser settings in this study were taken and modified from a previous experiment ${ }^{10}$ that

Table 1. Comparison of Baseline Characteristics in the Study Groups

\begin{tabular}{lccccc}
\hline & Low-Level Red Laser & Low-Level Infrared Laser & Combination Therapy & Placebo & \\
\hline Sex & & & & & \\
Females & $5(50)$ & $4(40)$ & $4(40)$ & $5(50)$ & $5(50)$ \\
Males & $5(50)$ & $6(60)$ & $6(60)$ & $10(100)$ \\
Total & $10(100)$ & $10(100)$ & $38.1(41)$ & $42(44)$ \\
Age & $35.9(29)$ & $38(34.5)$ & 0.512 \\
\hline
\end{tabular}

The sex distribution has been shown by No. (\%) and the age variable by mean (median).

Table 2. The Means and Standard Deviations (SD) of the Pain Scores in the Study Groups Over 7 Days After Extraction

\begin{tabular}{|c|c|c|c|c|c|c|c|c|}
\hline & Day 1 & Day 2 & Day 3 & Day 4 & Day 5 & Day 6 & Day 7 & \multirow{2}{*}{ Friedman Tes } \\
\hline & Mean \pm SD & Mean \pm SD & Mean \pm SD & Mean \pm SD & Mean \pm SD & Mean \pm SD & Mean \pm SD & \\
\hline Low-level red laser & $7.1 \pm 2.4$ & $5.1 \pm 2.2$ & $4.5 \pm 1.9$ & $3.3 \pm 2.1$ & $2.7 \pm 2.3$ & $2.2 \pm 2.4$ & $2.0 \pm 2.9$ & $P<0.001$ \\
\hline Low-level infrared laser & $5.0 \pm 2.8$ & $3.7 \pm 2.5$ & $4.0 \pm 2.8$ & $3.2 \pm 3.0$ & $3.1 \pm 3.0$ & $2.2 \pm 2.6$ & $1.8 \pm 2.1$ & $P=0.001$ \\
\hline Combination therapy & $4.5 \pm 2.5$ & $3.5 \pm 3.1$ & $2.7 \pm 2.8$ & $2.5 \pm 2.5$ & $2.4 \pm 3.0$ & $1.9 \pm 2.5$ & $1.6 \pm 2.1$ & $P<0.001$ \\
\hline Placebo & $4.8 \pm 3.0$ & $3.3 \pm 3.4$ & $3.0 \pm 3.4$ & $2.5 \pm 2.8$ & $2.2 \pm 2.6$ & $1.8 \pm 2.3$ & $1.7 \pm 2.4$ & $P<0.001$ \\
\hline Kruskal-Wallis test & $P=0.135$ & $P=0.463$ & $P=0.447$ & $P=0.834$ & $P=0.823$ & $P=0.948$ & $P=0.981$ & \\
\hline
\end{tabular}


Table 3. The Means and Standard Deviations (SD) of the Wound Healing Scores in the Study Groups on Days 3 and 7 After Extraction

\begin{tabular}{lllllll}
\hline & Day 3 & & & Day 7 & \\
\cline { 2 - 6 } & Mean \pm SD & Min & Max & Mean \pm SD & Min & 6 \\
\hline Low-level red laser & $6.6 \pm 1.05$ & 5 & 8.25 & $8.47 \pm 1.23$ & 10 & 5 \\
Low-level infrared laser & $6.44 \pm 1.52$ & 4 & 9 & $7.72 \pm 1.53$ & 5 \\
Combination therapy & $6.42 \pm 1.32$ & 4 & 8.5 & $7.95 \pm 1.32$ & 7 \\
Placebo & $6.3 \pm 1.78$ & 3.5 & 8.75 & $8.3 \pm 1.49$ & 10 \\
ANOVA & $\mathrm{F}=0.073, P=0.974$ & & & $\mathrm{~F}=0.585, P=0.629$ & \\
\hline
\end{tabular}

proved advantageous results of LLLT in decreasing the intensity of pain and swelling following the removal of the impacted third molars.

The VAS scores revealed no statistical difference in pain perception among the study groups. The insignificant effect of LLLT on pain reduction in the current study could be related to several reasons. The patients generally do not experience severe pain following tooth extraction and LLLT may be unable to reveal its pain-relieving properties in such conditions. Previous studies proved that laser therapy was effective in alleviating severe pain in patients affected by dry socket ${ }^{33,34}$; however, pain degree in those patients is terrible and not comparable with the little to moderate pain usually perceived after tooth extraction. Furthermore, the placebo effect of laser therapy may influence pain perception in the placebo group. It has been demonstrated that treatment with a high technology apparatus combined with a good relationship between the patient and clinician produces a positive psychological effect, which can attenuate the pain perceived by some patients. ${ }^{30,35-37}$

The healing of the dental socket following tooth extraction has long been considered as a subject of interest. The time required for the healing and closure of the extraction wound is annoying for most patients. Generally, patients complain that they cannot eat comfortably on the side of tooth extraction because of the presence of an empty socket, which is usually filled with food debris after eating. In the present study, the greatest healing scores were found in the red laser group, but the difference between the groups was small and not significant. According to the outcomes of this study, LLLT showed no effect on accelerating the healing process of extraction wounds. It should be noted that the participants in this study were systematically healthy. It is possible that the effect of LLLT on wound healing would be more remarkable in patients with a depressed immune system, such as diabetics or those underwent radiotherapy, who usually show more lengthy and problematic healing compared to healthy individuals. Furthermore, the method used to assess the healing rate in this study may not be precise enough to detect significant differences between the groups. Previous studies used different criteria to assess the effects of LLLT on wound healing after extraction. Most animal studies used histopathological assessment and found the positive effects of laser therapy on the healing of extraction wounds. ${ }^{19-21}$ Therefore, the significant healing effect of laser therapy might occur at the cellular rather than the clinical level.

The outcomes of this study are in agreement with the results of Elbay et $\mathrm{a}^{24}$ who found that LLLT was not capable of influencing postoperative pain after primary teeth extraction in children. Similarly, Paschoal and Santos-Pinto ${ }^{25}$ exhibited that LLLT neither decreased pain intensity nor increased the wound healing process following premolar extraction in adolescents. Others indicated that laser therapy was not effective to reduce pain and swelling after the surgical removal of impacted mandibular third molars. ${ }^{26}$ In contrast to the outcomes of this study, Park et $\mathrm{al}^{21}$ revealed that low-level diode laser irradiation caused the prominent expressions of genes and proteins related to the bone healing of extraction sockets in rats. Korany et $\mathrm{al}^{20}$ demonstrated that LLLT enhanced mineralization and bone healing in the sockets of rats irradiated with a GaAlAs diode laser. Mozzati et $\mathrm{al}^{38}$ reported that superpulsed diode laser radiation can be considered as a treatment option for subjects scheduled for tooth extraction, as it prevented the increase of inflammatory mediators and reduced pain after tooth extraction. Other studies exhibited that LLLT produced a positive effect on reducing the degree of pain in patients who underwent surgical interventions. ${ }^{10-18}$ Bjordal et $\mathrm{al}^{39}$ in a systematic review demonstrated that adequate doses of photoradiation can significantly alleviate acute inflammatory pain by suppressing the levels of biochemical markers.

It is believed that the biologic effects of low-power lasers are mainly dependent on the energy density $\left(\mathrm{J} / \mathrm{cm}^{2}\right)$ as well as the energy applied. The biostimulatory effects of low-power lasers are assumed to occur in a therapeutic window ranging from 0.01 to $10 \mathrm{~J} / \mathrm{cm}^{2}{ }^{40}$ However, the energy delivered to the tissue is as important as the dose, because the dose can be easily altered to a high or low value by using a thin or thick probe, leading to a confusing outcome. ${ }^{30}$ Although the energy and energy density used in this trial seemed appropriate, it is possible that the distance between the laser probe and the extraction socket and the presence of a blood clot preclude delivering the desired laser parameters to the target areas.

The limitations of this study were the small sample size and the difficulty in accessing the extraction socket 
because the laser probe used in this study had a relatively big size and stayed at the distance of approximately 10 $\mathrm{mm}$ away from the target site. Further studies with larger sample sizes are warranted to elucidate the effect of LLLT on reducing the complications of tooth extraction using different laser parameters. It is suggested that future studies use smaller laser probes to irradiate the extraction socket at a minimal distance or assess the effectiveness of LLLT in improving extraction wounds in subjects with a deficient immune system.

\section{Conclusion}

Under the conditions used in this study, LLLT with either a $660 \mathrm{~nm}$ or an $810 \mathrm{~nm}$ wavelength or their combination had no greater effect than the placebo laser on reducing pain and accelerating the wound healing process after lower molar extraction in adults.

\section{Ethical Considerations}

The study was approved by the ethics committee of Mashhad University of Medical Sciences. The study was also registered in Iranian Registry of Clinical Trials (identifier: IRCT20091118002736N2). The treatment procedure was explained completely for the patients and informed consent was taken before the study commencement. The study was in accordance with the principles stated in the Declaration of Helsinki.

\section{Conflict of Interests}

The authors declare no conflict of interest.

\section{Acknowledgements}

The authors would like to thank the Vice-Chancellor for Research of Mashhad University of Medical Sciences for the financial support of this project [grant number 940469]. The results presented in this work have been taken from a student thesis [thesis number: 2847].

\section{References}

1. Aida J, Ando Y, Akhter R, Aoyama H, Masui M, Morita M. Reasons for permanent tooth extractions in Japan. J Epidemiol. 2006;16(5):214-219. doi: 10.2188/jea.16.214.

2. Amler MH, Johnson PL, Salman I. Histological and histochemical investigation of human alveolar socket healing in undisturbed extraction wounds. J Am Dent Assoc. 1960;61:32-44. doi: 10.14219/jada.archive.1960.0152.

3. Bui $\mathrm{CH}$, Seldin EB, Dodson TB. Types, frequencies, and risk factors for complications after third molar extraction. J Oral Maxillofac Surg. 2003;61(12):1379-1389. doi: 10.1016/j.joms.2003.04.001.

4. Farivar S, Malekshahabi T, Shiari R. Biological effects of low level laser therapy. J Lasers Med Sci. 2014;5(2):58-62.

5. Holanda VM, Chavantes MC, Wu X, Anders JJ. The mechanistic basis for photobiomodulation therapy of neuropathic pain by near infrared laser light. Lasers Surg Med. 2017;49(5):516-524. doi: 10.1002/lsm.22628.

6. Pol R, Ruggiero T, Gallesio G, Riso M, Bergamasco L,
Mortellaro C, et al. Efficacy of Anti-Inflammatory and Analgesic of Superpulsed Low Level Laser Therapy After Impacted Mandibular Third Molars Extractions. J Craniofac Surg. 2016;27(3):685-690. doi: 10.1097/ SCS.0000000000002523.

7. Eshghpour M, Shaban B, Ahrari F, Erfanian M, Shadkam E. Is low-level laser therapy effective for treatment of neurosensory deficits arising from sagittal split ramus osteotomy? J Oral Maxillofac Surg. 2017;75(10):2085-2090. doi: 10.1016/j.joms.2017.04.004.

8. Moosavi H, Arjmand N, Ahrari F, Zakeri M, Maleknejad F. Effect of low-level laser therapy on tooth sensitivity induced by in-office bleaching. Lasers Med Sci. 2016;31(4):713-719. doi: 10.1007/s10103-016-1913-z.

9. Sardari F, Ahrari F. The effect of low-level helium-neon laser on oral wound healing. Dent Res J (Isfahan). 2016;13(1):2429. doi: 10.4103/1735-3327.174693.

10. Eshghpour M, Ahrari F, Takallu M. Is low-level laser therapy effective in the management of pain and swelling after mandibular third molar surgery? J Oral Maxillofac Surg. 2016;74(7):1322.e1-e8. doi: 10.1016/j.joms.2016.02.030.

11. Aras $M H$, Güngörmüş $M$. The effect of low-level laser therapy on trismus and facial swelling following surgical extraction of a lower third molar. Photomed Laser Surg. 2009;27(1):21-24. doi: 10.1089/pho.2008.2258.

12. Kazancioglu HO, Ezirganli S, Demirtas N. Comparison of the influence of ozone and laser therapies on pain, swelling, and trismus following impacted third-molar surgery. Lasers Med Sci. 2014;29(4):1313-1319. doi: 10.1007/s10103-0131300-y.

13. Markovic A, Todorovic LJ. Effectiveness of dexamethasone and low-power laser in minimizing oedema after third molar surgery: a clinical trial. Int J Oral Maxillofac Surg. 2007;36(3):226-229. doi: 10.1016/j.ijom.2006.10.006.

14. Kahraman SA, Cetiner S, Strauss RA. The effects of transcutaneous and intraoral low-level laser therapy after extraction of lower third molars: A randomized single blind, placebo controlled dual-center study. Photomed Laser Surg. 2017;35(8):401-407. doi: 10.1089/pho.2016.4252.

15. Saber K, Chiniforush N, Shahabi S. The effect of low level laser therapy on pain reduction after third molar surgery. Minerva Stomatol. 2012;61(7-8):319-322.

16. Landucci A, Wosny AC, Uetanabaro LC, Moro A, Araujo MR. Efficacy of a single dose of low-level laser therapy in reducing pain, swelling, and trismus following third molar extraction surgery. Int J Oral Maxillofac Surg. 2016;45(3):392-398. doi: 10.1016/j.ijom.2015.10.023.

17. Merigo E, Vescovi P, Margalit M, Ricotti E, Stea S, Meleti $\mathrm{M}$, et al. Efficacy of LLLT in swelling and pain control after the extraction of lower impacted third molars. Laser Ther. 2015;24(1):39-46. doi: 10.5978/islsm.15-OR-05.

18. Batinjan G, Zore Z, Čelebić A, Papić M, Gabrić Pandurić D, Filipović Zore I. Thermographic monitoring of wound healing and oral health-related quality of life in patients treated with laser (aPDT) after impacted mandibular third molar removal. Int JOral Maxillofac Surg. 2014;43(12):15031508. doi: 10.1016/j.ijom.2014.09.003.

19. Takeda Y. Irradiation effect of low-energy laser on alveolar bone after tooth extraction. Experimental study in rats. Int J Oral Maxillofac Surg. 1988;17(6):388-391. doi: 10.1016/ 
s0901-5027(88)80070-5.

20. Korany NS, Mehanni SS, Hakam HM, El-Maghraby EM. Evaluation of socket healing in irradiated rats after diode laser exposure (histological and morphometric studies). Arch Oral Biol. 2012;57(7):884-891. doi: 10.1016/j. archoralbio.2012.01.009.

21. Park JB, Ahn SJ, Kang YG, Kim EC, Heo JS, Kang KL. Effects of increased low-level diode laser irradiation time on extraction socket healing in rats. Lasers Med Sci. 2015;30(2):719-726. doi: 10.1007/s10103-013-1402-6.

22. Noba C, Mello-Moura ACV, Gimenez T, Tedesco TK, Moura-Netto C. Laser for bone healing after oral surgery: systematic review. Lasers Med Sci. 2018; 33(3):667-674. doi: 10.1007/s10103-017-2400-x

23. Weber JBB, Camilotti RS, Jasper J, Casagrande LCO, Maito F. Effect of low-level laser therapy on tissue repair after dental extraction in rats administered zoledronic acid and dexamethasone. J Biomed Opt. 2017;22(5):58001. doi: 10.1117/1.JBO.22.5.058001.

24. Elbay ÜŞ, Tak Ö, Elbay M, Uğurluel C, Kaya C. Efficacy of low-level laser therapy in the management of postoperative pain in children after primary teeth extraction: A randomized clinical trial. Photomed Laser Surg. 2016;34(4):171-177. doi: 10.1089/pho.2015.4045.

25. Paschoal MA, Santos-Pinto L. Therapeutic effects of lowlevel laser therapy after premolar extraction in adolescents: a randomized double-blind clinical trial. Photomed Laser Surg. 2012;30(9):559-564. doi: 10.1089/pho.2012.3243.

26. Brignardello-Petersen R, Carrasco-Labra A, Araya I, Yanine N, Beyene J, Shah PS. Is adjuvant laser therapy effective for preventing pain, swelling, and trismus after surgical removal of impacted mandibular third molars? A systematic review and meta-analysis. J Oral Maxillofac Surg. 2012;70(8):1789-1801. doi: 10.1016/j.joms.2012.01.008.

27. López-Ramírez M, Vílchez-Pérez MA, Gargallo-Albiol J, Arnabat-Domínguez J, Gay-Escoda C. Efficacy of low-level laser therapy in the management of pain, facial swelling, and postoperative trismus after a lower third molar extraction. A preliminary study. Lasers Med Sci. 2012;27(3):559-566. doi: 10.1007/s10103-011-0936-8.

28. Amarillas-Escobar ED, Toranzo-Fernández JM, MartínezRider R, Noyola-Frías MA, Hidalgo-Hurtado JA, Serna $\mathrm{VM}$, et al. Use of therapeutic laser after surgical removal of impacted lower third molars. J Oral Maxillofac Surg. 2010;68(2):319-324. doi: 10.1016/j.joms.2009.07.037.

29. Bidar M, Moushekhian S, Gharechahi M, Talati A, Ahrari F, Bojarpour M. The effect of low level laser therapy on direct pulp capping in dogs. J Lasers Med Sci. 2016;7(3):177183. doi: $10.15171 / \mathrm{jlms} .2016 .31$.

30. Madani AS, Ahrari F, Nasiri F, Abtahi M, Tunér J. Low-level laser therapy for management of TMJ osteoarthritis. Cranio. 2014;32(1):38-44. doi: 10.1179/0886963413Z.0000000004.

31. Kass A. Does the light of soft lasers or of combination soft and middle-power lasers improve wound healing in rats? Continuing studies. Biomed Tech (Berl). 1990;35(7-8):154157. doi: 10.1515/bmte.1990.35.7-8.154. [In German]

32. Agha-Hosseini F, Moslemi E, Mirzaii-Dizgah I. Comparative evaluation of low-level laser and $\mathrm{CO}_{2}$ laser in treatment of patients with oral lichen planus. Int J Oral Maxillofac Surg. 2012;41(10):1265-1269. doi: 10.1016/j. ijom.2012.06.001.

33. Eshghpour M, Ahrari F, Najjarkar NT, Khajavi MA. Comparison of the effect of low level laser therapy with alvogyl on the management of alveolar osteitis. Med Oral Patol Oral Cir Bucal. 2015;20(3):e386-e392. doi: 10.4317/ medoral.20375.

34. Kaya GŞ, Yapici G, Savaş Z, Güngörmüş M. Comparison of alvogyl, SaliCept patch, and low-level laser therapy in the management of alveolar osteitis. J Oral Maxillofac Surg. 2011;69(6):1571-1577. doi: 10.1016/j.joms.2010.11.005.

35. Ahrari F, Madani AS, Ghafouri ZS, Tunér J. The efficacy of low-level laser therapy for the treatment of myogenous temporomandibular joint disorder. Lasers Med Sci. 2014;29(2):551-557. doi: 10.1007/s10103-012-1253-6.

36. Moosavi H, Maleknejad F, Sharifi M, Ahrari F. A randomized clinical trial of the effect of low-level laser therapy before composite placement on postoperative sensitivity in class V restorations. Lasers Med Sci. 2015;30(4):1245-1249. doi: 10.1007/s10103-014-1565-9.

37. Bayani S, Rostami S, Ahrari F, Saeedipouya I. A randomized clinical trial comparing the efficacy of bite wafer and low level laser therapy in reducing pain following initial arch wire placement. Laser Ther. 2016;25(2):121-129. doi: 10.5978/islsm.16-OR-10.

38. Mozzati M, Martinasso G, Cocero N, Pol R, Maggiora M, Muzio G, et al. Influence of superpulsed laser therapy on healing processes following tooth extraction. Photomed Laser Surg. 2011;29(8):565-571. doi: 10.1089/ pho.2010.2921.

39. Bjordal JM, Johnson MI, Iversen V, Aimbire F, LopesMartins RA. Low-level laser therapy in acute pain: a systematic review of possible mechanisms of action and clinical effects in randomized placebo-controlled trials. Photomed Laser Surg. 2006;24(2):158-168. doi: 10.1089/ pho.2006.24.158

40. Jahanbin A, Ramazanzadeh B, Ahrari F, Forouzanfar A, Beidokhti M. Effectiveness of Er:YAG laser-aided fiberotomy and low-level laser therapy in alleviating relapse of rotated incisors. Am J Orthod Dentofacial Orthop. 2014;146(5):565-572. doi: 10.1016/j.ajodo.2014.07.006 